\title{
THE EFFECT OF SALIVA AND BLOOD CONTAMINATION ON THE BOND CHARACTERISTICS OF METAL BRACKET BONDED BY LIGHT CURED CYANOACRYLATE ADHESIVE
}

\author{
Ahmad Mohammad Hafez* and Essam Abdelalim Nassar**
}

\begin{abstract}
Purpose: This study was aimed to evaluate the effect of saliva and blood contamination on shear bond strength of metal brackets bonded with light cured cyanoacrylate adhesive.

Material and methods: The study was conducted on 75 extracted upper first premolars. Metal orthodontic brackets were bonded to the buccal surfaces of the premolars using Smart bond LC adhesive. The teeth were divided into 5 equal groups. In group I no the teeth were not subjected to contamination. In Group II and III the same procedures were done as in in group I except that the etched enamel was contaminated by saliva and blood respectively for 15 seconds. In group IV and V the same procedures were followed as in group II and III except that the saliva and blood contamination were washed with water for 10 seconds. The shear bond strengths were recorded using universal testing machine. The amount of adhesive remaining on the tooth was evaluated after debonding. The collected data were statistically analyzed using One-way analysis of variance (ANOVA) and LSD tests.
\end{abstract}

Results: The results revealed that no significant differences were found in the bond strength between the control group (without contamination), saliva contamination group without washing and saliva contamination group with washing $(\mathrm{P}>0.05)$. On the other hand, blood contamination significantly reduced the bond strength in comparison the saliva contamination or control groups $(\mathrm{P}<0.05)$. In addition, washing after blood contamination provided significantly higher bond strength than without washing $(\mathrm{P}<0.05)$.

Conclusion: Saliva contamination had no pronounced deleterious effect on the bond strength of Smart bond LC. On the other hand, blood contamination had pronounced deleterious effect on the bond strength. However, washing with water significantly reduced this effect.

\section{INTRODUCTION}

Nowadays, bonding of orthodontic brackets to tooth enamel is considered one of the most common procedures in orthodontic practice. Enamel etching, application of primer and resin are the main steps of a typical bonding procedure..$^{1,2}$

\footnotetext{
* Lecturer, Department of Orthodontics, Faculty of Dentistry, Mansoura University, Mansoura, Egypt.

**Associate Professor, Department of Orthodontics, Faculty of Dentistry, Mansoura University, Mansoura, Egypt.
} 
The success of such technique depends on the bond strength between enamel and bracket. The bond strength is potentially affected by many factors including; etchant type and time, adhesive composition and mode of curing and bracket type and base design. ${ }^{3-7}$ The ideal adhesive system should provide bond strength high enough to withstand forces of orthodontic appliances as well as masticatory forces. On the other hand, debonding should be done easily without any deleterious effects on the enamel such as fractures or cracking. ${ }^{5}$ Reynolds suggested a range of 6-8 MPa for clinically successful bonding. ${ }^{8}$

The bonding procedures could be done in different situations that have negative deleterious effects on the bond strength and hence increase the faulier rate of the bonded brackets. Among these situations is the contamination with water, saliva and blood. ${ }^{9-12}$ The suscesapility of such condition increases during bracket bonding to surgically exposed tooth or partially erupted. ${ }^{9}$

Primers and adhesives of different composition and curing modes have been developed aiming to enhance the bond strength and reduce the failure rates of the brackets. ${ }^{13-16}$ Among these adhesives is the cyanoacrylate adhesive. It is a moisture activated and does not need the utilization of a primer during bonding. ${ }^{8}$ It could be utilized in situations where isolation control is questionable such as exposure of impacted tooth or patients with excessive salivation. Örtendahl and Örtengren and Bishara et al reported that cyanoacrylate has good bond strength comparable to other orthodontic adhesives. ${ }^{17-20}$ On the other hand, other studies showed that cyanoacrylate has poor performance and unstable bond strength. ${ }^{21,22}$

A new generation of cyanoacrylate was developed. It is a light and moisture activated adhesive (dual cured). However, little data was available about it. Cacciafest et $\mathrm{al}^{9}$ found that light cured cyanoacrylate adhesive had a lesser
SBS than transbond XT adhesive in dry condition. On the other hand, it had significantly higher bond strength under moist or contaminated conditions. The present study was conduct to evaluate the effect of saliva and blood contamination on the shear bond strength of metal bracket bonded by light cured cyanoacrylate adhesive.

\section{MATERIALS AND METHODS}

Seventy five freshly human upper first premolars extracted as a part of orthodontic treatment regimen were collected and stored in $0.1 \%$ thymol solution. The teeth were devoid of any cracks, caries, attrition, restoration and not subjected to any pretreatment chemical agents. The teeth were invested into plastic rings ( $3 \mathrm{~cm}$ in diameter and height) using a selfcuring acrylic resin(Figure 1). The buccal surfaces of the teeth were adjusted to be out of the mounting acrylic. Then the teeth were divided into five equal groups $(n=15)$.

The sample size was estimated by $\mathrm{G}^{*}$ Power software version 3.0.10. assuming type I statistical error of $5 \%$, this study was designed to have a power of $80 \%$ based on the previous study by Cacciafest et $\mathrm{al}^{9}$ studying the effect of water and saliva contamination on the shear bond strength of a new light-cured cyanoacrylate adhesive. The means were $3.11 \pm 1.5$ and $5.17 \pm 2.66$ for water and saliva contamination respectively. Therefore, the calculated sample size was 15 teeth per group.

Metal orthodontic brackets (Oramco, USA) were bonded to the buccal surfaces of the teeth Smartbond LC (Gestenco, Gotenburg, Sweden). In group I the teeth were not subjected to either blood or saliva contamination during bonding (control group). On the other hand, in group II and III the teeth were subjected to saliva and blood contamination after enamel etching during bracket bonding respectively. In group IV and V the saliva and blood contamination were washed with water. 


\section{Bonding procedures:}

In Group I: $37 \%$ phosphoric acid etch (manufacture name) was applied to the enamel surfaces for 30 seconds. Then the teeth were washed thoroughly with water and kept wet (not dry). A thin layer Smartbond LC was applied to the base of the bracket then the bracket was placed in the correct position on the enamel surface and pressed firmly. Then the adhesive was light cured for 20 seconds

In Group II and III: the same procedures were done as in in group I except that the etched enamel was contaminated by saliva and blood respectively for 15 seconds. ${ }^{10}$

In group IV and V: the same procedures were followed as in group II and III respectively except that the saliva and blood contamination were washed with water for 10 seconds.

All specimens were incubated30 minutes after bonding in distilled water at $37 \pm 0.1^{\circ} \mathrm{C}$ for 24 hours. Then the specimens were thermocycled 500 times between two water baths held at $5^{\circ} \mathrm{C}$ and $55^{\circ} \mathrm{C}$ with a dwell time of $30 \mathrm{~s}$ in each path before conducting the shear bond strength test.

\section{Evaluation of shear bond strength:}

In debonding procedure the specimens were oriented horizontally on the lower fixed member of the universal testing machine (Lloyed, Type 500, Lloyed Instrument, England). Shear dislodging force was applied through a knife edged metal bar attached to the upper member of the testing machine that moves at a crosshead speed of $2 \mathrm{~mm} / \mathrm{min}$ (Figure 2). The metal bar was adjusted to apply the load under the incisal wings of each bonded bracket and parallel to the long axis of each mounted tooth. Loads required to dislodge each bracket were recorded in Newtons and the shear bond strength was calculated in MPa using the following equation:

$$
\mathbf{d}=\frac{\mathbf{F}}{\mathbf{A}}
$$

Where, $\mathrm{d}=$ Shear bond strength, $\mathrm{F}=$ Load at dislodgement in Newtons, $\mathrm{A}=$ Bracket base surface area in $\mathrm{mm}$.

The amount of adhesive remaining on the tooth was evaluated after debonding using the Adhesive Remnant Index (ARI). The ARI has a range of 0 (no adhesive left on the enamel surface) to 3 (all adhesive left on the enamel surface). Less than $50 \%$ of the adhesive left on the enamel is 1 , while more than $50 \%$ of adhesive left on the enamel is 2 .

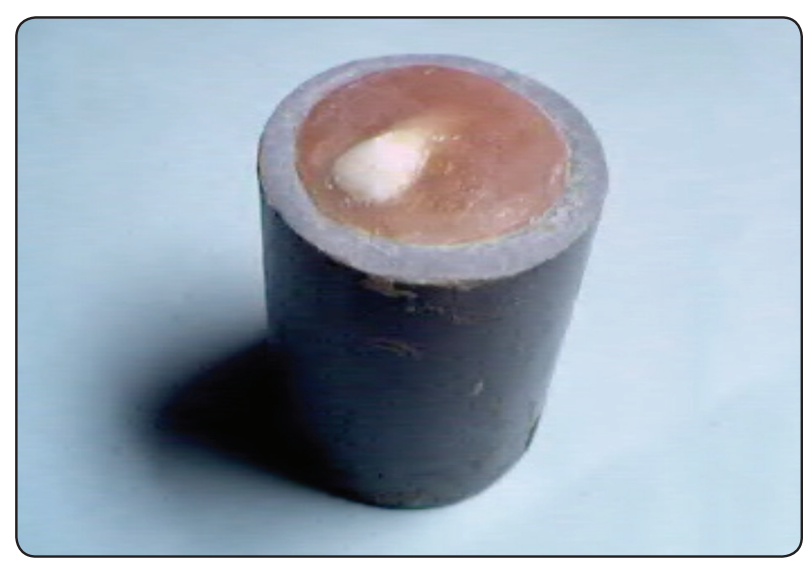

Fig. (1) Tooth invested into metal ring using self-curing acrylic resin.

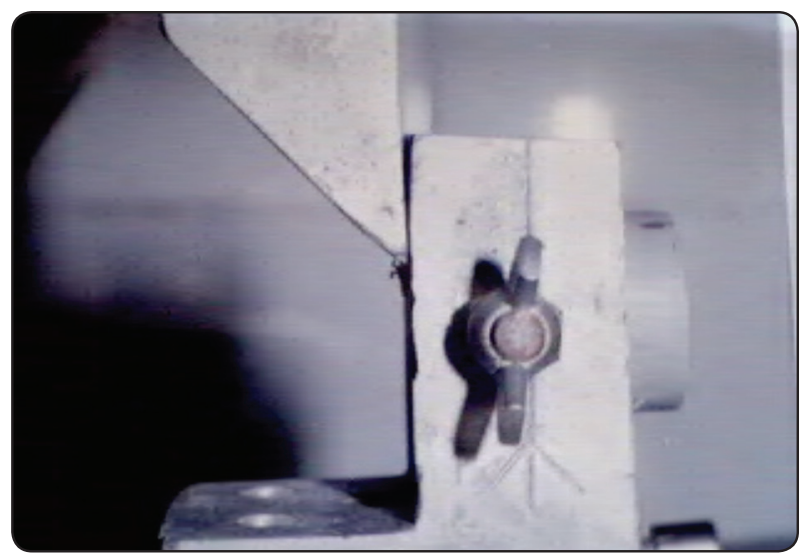

Fig. (2) Shear dislodging force applied via a knife edged metal bar attached to the upper member of the testing machine. 


\section{Statistical analysis}

The collected data was statistically analyzed using SPSS. The means and standard deviations of the shear bond strength of the five studied subgroups were calculated. One-way analysis of variance (ANOVA) and LSD tests were utilized to compare between different adhesives within each group. Unpaired student t-test was used to determine the effect of force on SBS for each adhesive system. Kruskal Wallis test was utilized to evaluate the significant difference in ARI scores between the five studied groups. Chi-square test was used to determine the differences in the ARI scores of the Smart bond LC adhesive with different contamination protocol. Significance for all statistical tests was predetermined at $\mathrm{P}<0.05$.

\section{RESULTS}

The means and standard deviations of shear bond strength of the five studied groups with different protocols of contaminations are presented in table 1 and figure 1. The bond strength of Smartbond LC without contamination showed the highest values while contamination with blood without washing had the lowest value of bond strength.

The results of ANOVA revealed significant differences in the bond strength between the studied groups with the different protocols of contaminations $(\mathrm{P}<0.05)$. The results of LSD test revealed that no significant differences were found in the bond strength between the control group (without contamination), saliva contamination group without washing and saliva contamination group with washing $(\mathrm{P}>0.05)$. On the other hand, blood contamination significantly reduced the bond strength in comparison the saliva contamination or control groups $(\mathrm{P}<0.05)$. In addition, washing after blood contamination provided significantly higher bond strength than without washing $(\mathrm{P}<0.05)$.
TABLE (1) The mean and standard deviation (SD) of the shear bond strength (MPa) of Smart bond LC adhesive with different contamination protocols and the result of ANOVA and LSD tests.

\begin{tabular}{|c|c|c|c|}
\hline \multirow{2}{*}{ Group } & \multirow{2}{*}{$\begin{array}{l}\text { Shear bond } \\
\text { strength } \\
(\text { Mean } \pm \mathrm{SD})\end{array}$} & \multicolumn{2}{|c|}{ ANOVA } \\
\hline & & $\mathrm{F}$ & $\mathrm{P}$ \\
\hline $\begin{array}{l}\text { Control } \\
\text { (no contamination) }\end{array}$ & $6.93 \pm 1.16^{\mathrm{A}}$ & \multirow{5}{*}{35.431} & \multirow{5}{*}{.000} \\
\hline Saliva contamination & $6.66 \pm 1.34^{\mathrm{C}}$ & & \\
\hline Blood Contamination & $1.93 \pm 1.43^{\mathrm{ABC}}$ & & \\
\hline $\begin{array}{l}\text { Saliva contamination } \\
\text { then washing }\end{array}$ & $6.73 \pm 1.48^{\text {B }}$ & & \\
\hline $\begin{array}{l}\text { Blood contamination } \\
\text { then washing }\end{array}$ & $4.93 \pm 1.43^{\mathrm{ABC}}$ & & \\
\hline
\end{tabular}

Means with the same superscript letters in the same column are statistically different according to LSD test. Significance: $\mathbf{P}<0.05$.

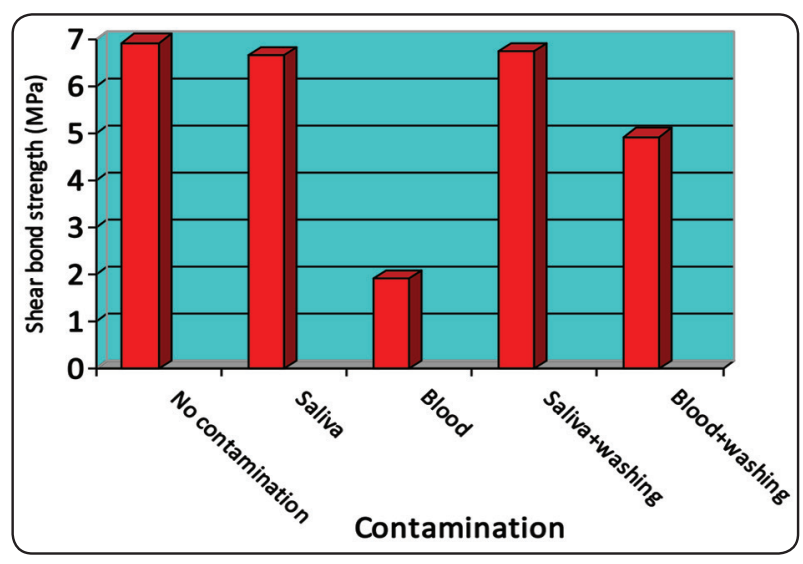

Fig. (3) The mean shear bond strength (MPa) of Smart bond LC adhesive with different contamination protocols.

The ARI scores of the Smart bond LC adhesive with different contamination protocol are illustrated in table 2. The results of Kruskal Wallis test revealed that there was significant difference in ARI score between the five studied groups $(\mathrm{P}<0.000)$. The Chi square test showed that, in the control and saliva contamination with and without washing groups in the majority of the teeth more than $50 \%$ of the adhesive was left on the enamel surface. On the other hand, in blood contamination group no adhesive was left on the enamel in the majority of the teeth. 
In blood contamination and washing group less than $50 \%$ of the adhesive was left on the enamel.

TABLE (2) The adhesive remnant index (ARI) of Smart bond Smart bond LC adhesive with different contamination protocols and the results of Chi-square test.

\begin{tabular}{|c|c|c|c|c|c|c|}
\hline \multirow[t]{2}{*}{ Group } & \multicolumn{4}{|c|}{$\begin{array}{c}\text { Adhesive Remnant } \\
\text { Index (ARI) }\end{array}$} & \multirow{2}{*}{ 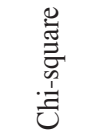 } & \multirow{2}{*}{ 客 } \\
\hline & 0 & 1 & 2 & 3 & & \\
\hline $\begin{array}{l}\text { Control (no } \\
\text { contamination) }\end{array}$ & 0 & 1 & 11 & 3 & 11.200 & .004 \\
\hline Saliva contamination & 0 & 2 & 12 & 1 & 14.800 & .001 \\
\hline Blood Contamination & 8 & 4 & 2 & 1 & 7.667 & .053 \\
\hline $\begin{array}{l}\text { Saliva contamination } \\
+ \text { washing }\end{array}$ & 1 & 3 & 10 & 1 & 14.600 & .002 \\
\hline $\begin{array}{l}\text { Blood contamination } \\
+ \text { washing }\end{array}$ & 4 & 7 & 3 & 1 & 5.000 & .172 \\
\hline
\end{tabular}

The ARI score; $0=$ no adhesive left on the enamel surface, $1=$ less than $50 \%$ of the adhesive left on the enamel, 2 = more than $50 \%$ of the adhesive left on enamel, $3=$ all adhesive left on the enamel surface.

\section{DISCUSSION}

Direct bonding of orthodontic attachments has improved the clinical practice of orthodontics. ${ }^{9}$ Traditionally bonding procedures should be done in complete dry and isolated field to obtain good bond strength. Saliva and blood contamination negatively affect bond strength and may result in bond faulier. Bond failure of orthodontic attachments has many disadvantages. It leads to rebonding with lesser bond strength. Also, it increases treatment time and cost. The present study evaluated the effect of saliva and blood contamination on the shear bond strength of orthodontic brackets bonded with light cured cyanoacrylate orthodontic adhesive. This adhesive has the advantage that it need wet surface (not dry) for polymerization.

The results of the present study revealed that Smart bond LC provided shear bond strength $(6.93 \pm 1.16 \mathrm{MPa})$ that lies in clinically acceptable range as described by Reynolds ${ }^{8}$. In addition the bond strength of this type of cyanoacrylate is greater than that of the older version as reported by many authors. ${ }^{18,19}$ However, Smart bond LC is a dual cure (moisture and light activated) while the older version was moisture activated only.

Regarding the effect of saliva contamination, the results of the present study showed that saliva contamination with or without washing $(6.73 \pm 1.48$, and $6.66 \pm 1.34$ respectively) slightly reduced the shear bond strength. However, this reduction was not statistically significant $(\mathrm{P}<0.05)$ and still within the clinically acceptable range. Hence, it is advantageous to use Smart bond LC when saliva contamination prevention is difficult. This could be attributed to that this type of adhesive is moisture activated and has hydrophilic property. This result was in line with those of Cacciafesta et $\mathrm{al}^{9,23}$. On the other hand, the results of Prasad et $\mathrm{al}^{10}$, Santosa et $\mathrm{al}^{11}$, Cacciafesta et $\mathrm{al}^{23}$ and Deprá ${ }^{24}$ presented significant reduction in the bond strength of conventional adhesive types when subjected to saliva contamination during the bonding procedures. This was attributed to the hydrophobic nature of the conventional adhesives.

The result of the present study also revealed that blood contamination significantly reduced the shear bond strength. This could be attributed to composition of the blood contains differ organic and inorganic substance than saliva. In addition blood has clotting mechanism. These factors make blood provides a greater mechanical barrier than saliva that significantly reduced the bond strength. These findings were in harmony with those of other studies. ${ }^{10,25,26}$ On the other hand, the results were in disagreement with those of Oonsombat et $\mathrm{al}^{27}$. The differences could be attributed to the deference in the adhesive and blood used. In the present study, fresh blood was used while blood mixed with anticoagulants was used in other study. However, the negative effect of blood contamination was significantly reduced when blood contamination was washed as the shear bond strength after blood contamination followed by washing 
$(4.93 \pm 1.43 \mathrm{MPa})$ was significantly higher than without washing $(1.93 \pm 1.43 \mathrm{MPa})$. This could be explained by washing with water remove the blood from the enamel surface and hence the mechanical barrier was reduced and the bond strength was enhanced. However, this enhancement of the bond strength did not reach the level of bond strength without blood contamination as washing could not completely remove blood from the etched enamel. Therefore, it is recommended to wash the contaminated enamel surface before bonding to improve the bond strength.

Regarding the ARI the results of the present study revealed that in the control and saliva contamination with and without washing groups more than $50 \%$ of the adhesive was left on the enamel surface. This could be attributed to the hydrophobic nature of the conventional adhesives. On the other hand, in the blood contamination group the no adhesive was left on the enamel. This could be explained by the blood acts as a mechanical barrier or separating medium between the adhesive and the enamel surface.

\section{CONCLUSIONS}

According to the results of the present study the following could be concluded:

- Smart bond LC had acceptable shear bond strength.

- Saliva contamination had no pronounced deleterious effect on the bond strength of Smart bond LC.

- Blood contamination had pronounced deleterious effect on the bond strength. However, washing with water significantly reduced this effect.

\section{REFERENCES}

1. Bishara SE, Gordan VV, VonWald L, Olson ME. Effect of an acidic primer on shear bond strength of orthodontic brackets. Am J Orthod Dentofacial Orthop. 1998; 114:243-247.

2. Bishara SE, Oonsombat C, Soliman MMA, Warren JJ, Laffoon JF, Ajlouni R. Comparison of Bonding Time and Shear Bond Strength Between a Conventional and a New Integrated Bonding System. Angle Orthod 2005; 75:237-242.

3. Faltermeier A, Behr M, Müssigc D. A comparative evaluation of bracket bonding with 1-, 2, and 3component adhesive systems. Am J Orthod Dentofacial Orthop 2007;132:144.e1-144.e5.

4. Urabe H, Rossouw PE, Titley KC, Yamin C. Combination of etchants, composite resins, and bracket systems: An important choice of orthodontic bonding procedures. Angle Orthod 1999;69:267-275.

5. Talpur M, Cunningham SJ, Moles DR, and Steven P. Jones SP. The relationship between base dimensions, force to failure, and shear bond strengths of bondable molar tubes. Angle Orthod 2012; 82: 536-540.

6. Soderquist SA, Drummond JL, Evans CA. Bond strength evaluation of ceramic and stainless steel bracket bases subjected to cyclic tensile loading. Am J Orthod Dentofacial Orthop. 2006;129:175.e7-175.e12.

7. Daub J, Berzins DW, Linn BJ, Bradley TG. Bond strength of direct and indirect bonded brackets after thermocycling. Angle Orthod 2006;76:295-300.

8. Reynolds IR. A review of direct orthodontic bonding. Br J Orthod, 1979: 2: 171-178.

9. Cacciafest V, Sfondrini MF, Gatti S, Klersy C. Effect of water and saliva contamination on the shear bond strength of a new light-cured cyanoacrylate adhesive. Progress in Orthodontics, 2007; 8: 100-111.

10. Prasad M, Mohamed S, Nayak K, Shetty SK, Talapaneni AK. Effect of moisture, saliva, and blood contamination on the shear bond strength of brackets bonded with a conventional bonding system and self-etched bonding system. J Nat Sc Biol Med 2014;5:123-129.

11. Santosa BM, Pithonb MM, Ruellasc AC, Sant'Annac EF. Shear bond strength of brackets bonded with hydrophilic and hydrophobic bond systems under contamination. Angle Orthod. 2010;80:963-967.

12. Akdeniz BS, Oz AA, Arici N, Demir O, Arici S. Using Hemostatic Agents During Orthodontic Bonding: An In Vitro Study. Turkish J Orthod 2015;28:38-43.

13. Davari AR, Yassaei S, Daneshkazemi AR, Yosefi MH. Effect of different types of enamel conditioners on the bond strength of orthodontic brackets. J Contemp Dent Pract 2007;8:36-43. 
14. Bishara SE, Soliman M, Laffoon JF, Warren J. Shear Bond Strength of a New High Fluoride Release Glass Ionomer Adhesive. Angle Orthod 2008; 78: 125-128.

15. Ozer M, Bayram M, Dincyurek C, Tokalak F. Clinical bond failure rates of adhesive precoated self-ligating brackets using a self-etching primer. Angle Orthod. 2014:84:155-160.

16. Vicente A, Bravo LA, Romero M, Ortiz AJ, Canteras M. A Comparison of the shear bond strength of a resin cement and two orthodontic resin adhesive systems. Angle Orthod 2004;75:109-113.

17. Örtendahl TW, Örtengren U. A new orthodontic bonding adhesive. J Clin Orthod, 2000; 34: 50-54.

18. Bishara SE, VonWald L, Laffoon JF, Warren J. Effect of using a new cyanoacrylate adhesive on the shear bond strength of orthodontic brackets. Angle Orthod, 2001; 71: 466-469.

19. Bishara S.E., Laffoon J.F., VonWald L., and Warren J. Effect of time on the shear bond strength of cyanoacrylate and composite orthodontic adhesives. Am J Orthod Dentofacial Orthop, 2002; 121: 297-300.

20. Bishara SE, Laffoon JF, VonWald L, Warren JJ. The effect of repeated bonding on the shear bond strength of different orthodontic adhesives. Am J Orthod Dentofacial Orthop, 2002; $121: 521-525$

21. Al-Munajed MK, Gordon PH, McCabe JF. The use of a cyanoacrylate adhesive for bonding orthodontic brackets: an ex-vivo study. J Orthod, 2000; 27: 255-260.
22. Le PT, Weinstein M, Borislow AJ, Braitman LE. Bond failure and decalcification: A comparison of cyanoacrylate and a composite resin bonding system in vivo. Am J Orthod Dentofacial Orthop, 2003; 123:624-627.

23. Cacciafesta V, Sfondrini MF, De Angelis M, Scribante A, Klersy C. Effect of water and saliva contamination on shear bond strength of brackets bonded with conventional, hydrophilic and self-etching primers. Am J Orthod Dentofacial Orthop 2003;123:633-640.

24. Deprá MB, Almeida JX, Cunha TMA, Lon LFS, Retamoso LB, Tanaka OM. Effect of saliva contamination on bond strength with a hydrophilic composite resin. Dental Press J Orthod. 2013;18:63-68

25. Oztoprak MO, Isik F, Sayinsu K, Arun T, Aydemir B. Effect of blood and saliva contamination on shear bond strength of brackets bonded with 4 adhesives. Am J Orthod Dentofacial Orthop 2007;131:238-242.

26. de Carvalho Mendonça EC, Vieira SN, Kawaguchi FA, Powers J, Matos AB. Influence of Blood Contamination on Bond Strength of a Self-Etching System. Eur J Dent 2010;4:280-286.

27. Oonsombat C, Bishara SE, Ajlouni R. The effect of blood contamination on the shear bond strength of orthodontic brackets with the use of a new self-etch primer. Am J Orthod Dentofacial Orthop 2003;123:547-550. 